\title{
La actualidad institucional y económica de España en el marco de la Unión Europea
}

\section{Current Institutional and Economic Developments in Spain within the Framework of the European Union}

\author{
Beatriz Iñarritu \\ Profesora de 'Deusto Business School' \\ Universidad de Deusto
}

\begin{abstract}
Sumario: I. Introducción.-II. El Estado de la Integración. 1. Debate en el Reino Unido en relación a la Unión Europea. 2. Islandia retira su solicitud de adhesión a la UE. 3. Gobernanza económica: el Semestre Europeo 2015. 4. Debate sobre la gobernanza económica europea: la ambiciosa propuesta española. 5. Acuerdo político sobre el Plan Juncker. 6. La Comisión propone una multa a España por el falseamiento del déficit público.III. Cuestiones generales de la actualidad económica. 1. BCE: Compra masiva de Deuda pública. 2. Mecanismo Europeo de Estabilidad: primera emisión de deuda con intereses negativos. 3. Acuerdo Trasatlántico UEEEUU: negociaciones pospuestas. 4. Competencia-ayudas públicas: investigación sobre las ayudas a las compañías eléctricas de once países y al sector bancario de cuatro países. 5. Competencia-abuso de posición de dominio: acusaciones a Google y Gazprom. 6. Bruselas recurre la decisión del Tribunal sobre las deducciones fiscales aplicadas por empresas españolas por la adquisición de empresas extranjeras. 7. Tribunal de Justicia: nuevo dictamen en contra de la Ley Hipotecaria española. 8. Competencia: autorización de compra de Jazztel por parte de Orange. 9. Inmigración: plan de acogida a solicitantes de asilo.
\end{abstract}

\section{Introducción}

En el primer semestre de 2015 el Banco Central Europeo ha iniciado un programa de compras masivas de deuda pública en la Eurozona con el que espera contribuir a la recuperación económica. El acuerdo sobre el Plan Juncker también favorecerá las inversiones en la UE y, aunque con retraso, las negociaciones sobre el polémico Tratado con Estados Unidos siguen adelante.

Destacan también las decisiones sobre política común de competencia que se han centrado en los últimos meses en las ayudas públicas recibidas 
por los sectores eléctrico y bancario y en las prácticas abusivas de Google y Gazprom.

\section{El estado de la integración}

\section{Debate en el Reino Unido en relación a la Unión Europea}

Tras la victoria del partido conservador en las elecciones generales de Mayo, el ministro de Exteriores británico, Philip Hammond, depositó en la Cámara de los Comunes el proyecto de ley para la convocatoria de un referéndum con el que los ciudadanos del Reino Unido decidirán sobre su pertenencia a la UE.

El proyecto de ley obliga a celebrar el referéndum antes del 31 de diciembre de 2017 y, para entonces, el primer ministro David Cameron esperaría haber conseguido un cambio en los Tratados, sin el cual, advirtió, difícilmente podrá convencer a los ciudadanos británicos de votar por permanecer en la UE.

Aunque el gobierno británico no ha hecho públicas sus exigencias en la negociación, fuentes expertas ya han apuntado determinadas medidas como la limitación de los derechos de los inmigrantes europeos, que, en efecto, estaba recogida en el programa electoral de los tories.

En este ámbito, altos responsables de las instituciones europeas se manifestaron en defensa de la libertad de circulación de personas aunque, según matizaron, no debería servir de excusa para aprovecharse de las prestaciones y hacer "turismo de seguridad social", tal como señaló Jyrki Kaitanen, vicepresidente de la Comisión.

Cameron pretendería conseguir alguna cláusula que le permita negar prestaciones de desempleo a los inmigrantes de la UE y compensaciones para los trabajadores con salarios más bajos, en forma de, por ejemplo, créditos fiscales.

Éste sería un acuerdo muy difícil puesto que provocaría una situación discriminatoria para los ciudadanos de la Unión, y el voto unánime de los Veintiocho para modificar los Tratados sería complejo. Además, las concesiones no se harán en un solo sentido, sino que habría que pactar una reciprocidad.

También señalan fuentes cercanas al gobierno británico que posiblemente Cameron defenderá la posibilidad de que la Cámara de los Comunes pueda vetar las normas comunitarias; también este cambio será difícil puesto que los otros 27 parlamentos exigirían la misma posibilidad. Y entonces la UE correría el riesgo de quedar paralizada. Y Londres también querría que se elimine de los Tratado la cláusula que establece que el propósito de la UE es avanzar hacia "una unión cada vez más estrecha", o al menos que se exima al Reino Unido de cumplirla. 


\section{Islandia retira su solicitud de adhesión a la UE}

En Marzo el gobierno conservador islandés retiró la candidatura del país para ingresar en la Unión Europea (UE).

Islandia había solicitado formalmente su ingreso en la UE en 2009, cuando el gobierno de este país estaba en manos de una coalición de socialdemócratas y verdes. Pero en los años siguientes, el proceso se vio dificultado por discrepancias persistentes, especialmente en materia de pesca y agricultura.

La situación se agravó en 2013 con la llegada al poder del actual gobierno conservador en Islandia, que lidera el primer ministro Sigmundur David Gunnlaugsson, hasta que las negociaciones quedaron prácticamente congeladas. El actual ejecutivo considera que puede defender mejor los intereses de su país sin formar parte de la UE.

\section{Gobernanza económica: el Semestre Europeo 2015}

A lo largo de los seis primeros meses de 2015, en el llamado "Semestre Europeo" se han dado los pasos previstos, los Exámenes Exhaustivos, los Planes nacionales y las Recomendaciones Específicas por país.

La Comisión publicaba el 26 de Febrero los Informes-País que incluían los Exámenes Exhaustivos de 16 Estados miembros, los que, según el "Informe del Mecanismo de Alerta" de Noviembre, debían ser analizados en profundidad en el marco del "Procedimiento de Desequilibrios Macroeconómicos 2015".

Respecto al Informe de España, la Comisión Europea valoraba los esfuerzos por reducir el déficit por debajo del $3 \%$ del PIB, un objetivo fijado para 2016, aunque al mismo tiempo advertía de que el país presentaba desequilibrios macroeconómicos, por lo que pidió "acciones decisivas".

"En España ha habido mejoras, pero aún hay riesgos", dijo en rueda de prensa el comisario europeo de Asuntos Económicos y Financieros, Pierre Moscovici, quien precisó que el país seguiría siendo sometido a la supervisión comunitaria.

En un comunicado, el ejecutivo comunitario precisaba que "pese a algunas mejoras en el proceso de reequilibrio de la balanza por cuenta corriente, los riesgos relacionados con los altos niveles de deuda pública y privada y la posición internacional de inversión negativa siguen mereciendo mucha atención en el contexto de desempleo muy elevado. La necesidad de actuar para reducir los riesgos de los efectos adversos en la economía española, dado su tamaño, y de contagios negativos a la Unión Económica y Monetaria es particularmente importante", añadía la Comisión.

En abril, los gobiernos nacionales remitieron a la Comisión sus respectivos Planes de Estabilidad y Convergencia y Planes Nacionales de Reforma. 
Según las nuevas previsiones incluidas en el Plan de Estabilidad español 2015-18, España conseguirá corregir el déficit público en 2018, once años después de que se comenzara a generar en 2008. Entonces conseguiría una brecha entre gastos e ingresos públicos de un mínimo 0,3\% del PIB.

Este camino será posible gracias al incremento en los ingresos públicos que, a su vez, será posible gracias al crecimiento económico previsto.

Para 2016, el objetivo no varía respecto a las previsiones anteriores y se mantiene en el $2,8 \%$, lo que implicaría cerrar el procedimiento abierto por Bruselas a España por déficit excesivo.

El Plan prevé, asimismo, una paulatina reducción del gasto público desde el 43,6\% del PIB del año pasado al 38,4\% en 2018 (casi cinco puntos porcentuales), aunque no será debido a nuevos recortes en el gasto sino al mayor ritmo de crecimiento del PIB. La estimación remitida a Bruselas prevé, asimismo, un nivel de ingresos públicos del 38,1\% del PIB en 2018, unos siete puntos menos que la media europea (45\%), Esta brecha se explica por el gran número de deducciones y bonificaciones en los impuestos, y por el enorme peso del fraude y de la economía sumergida.

Este menor nivel de ingresos públicos condiciona el techo del gasto público español, que también es muy inferior al gasto medio en la UE (en torno al $48 \%$ del PIB de media).
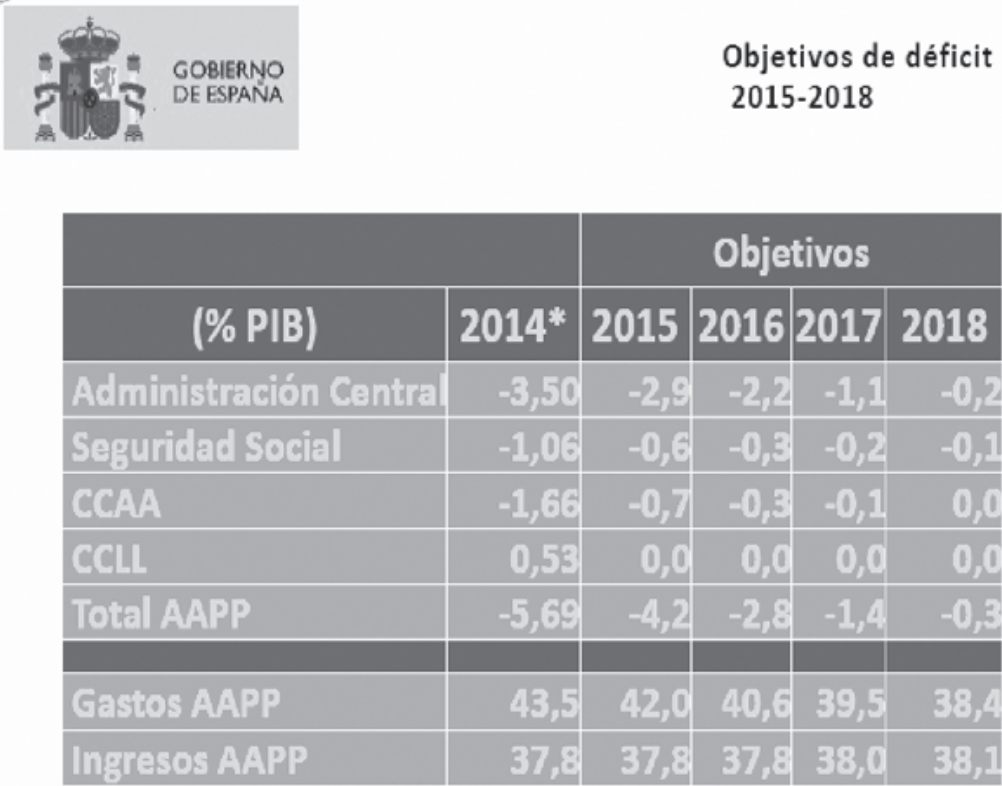

Fuente: Plan de Estabilidad de España 2015-18. 
La reducción del déficit previsto por el gobierno permitiría reducir la deuda. En 2015 el endeudamiento de las Administraciones alcanzaría su cota máxima hasta llegar al 98,9\% del PIB, para iniciar un descenso paulatino hasta el $93,2 \%$ en 2018 . Se trata de un nivel todavía muy elevado y alejado del objetivo del $60 \%$ que impone Bruselas y que España se comprometió a cumplir en 2020 en la Ley de Estabilidad Presupuestaria.

Por su parte, el Plan Nacional de Reformas español contemplaba cuatro ámbitos de actuación para este año: el impulso de las políticas activas de empleo, la moderación de las cotizaciones sociales de las empresas, las medidas de apoyo al trabajo autónomo y la reforma de la Formación Profesional para acelerar la creación de empleo juvenil.

Y en mayo, las Recomendaciones de la Comisión para España se agrupaban en cuatro temas: el control del déficit público, la conclusión de la reestructuración del sector bancario, la mejora de la eficiencia del mercado laboral y la aplicación de las reformas pendientes que faciliten el trabajo de las empresas.

La propuesta de este año resultaba ser menos específica y detallada que en años anteriores. Según Pierre Moscovici, comisario de Asuntos Económi$\cos$, Bruselas quiere ser "menos intrusiva" y es por ello que "las recomendaciones son ahora más amplias y estratégicas de lo que solían ser", afirmó.

Sin embargo, el ejecutivo europeo se mostró especialmente crítico en el apartado fiscal, ya que afirmaba ver "riesgo de que España no cumpla con las normas del Pacto de Estabilidad y Crecimiento", que obligan a situar el déficit público por debajo del $3 \%$ y la deuda en niveles inferiores al $60 \%$ del PIB.

Según la Comisión Europea, el esfuerzo fiscal previsto para España entre 2013 y 2016 estará por debajo del nivel recomendado, y "nuevas reformas estructurales serán necesarias en 2015 y 2016". Según las estimaciones del gobierno español, el déficit de este año se situará en el 4,2\% del Producto Interior Bruto (PIB) y el del que viene en el $2,8 \%$, pero la Comisión prevé cifras superiores, al 4,5\% y $3,5 \%$.

Otro de los puntos en los que más incidía Bruselas es el mercado laboral. En las recomendaciones alertaba de que el elevado desempleo de larga duración y la elevada segmentación del mercado laboral seguían "dañando la productividad". Advertía de que "en algunos sectores y compañías puede ser necesario en el corto plazo que los salarios crezcan por debajo de la productividad para crear empleos y alcanzar nuevas mejoras de productividad". El documento también señalaba que el porcentaje de la población con empleo temporal continuaba incrementándose en 2014, hasta alcanzar el $24 \%$ y cebándose especialmente en los jóvenes y trabajadores poco cualificados. 


\section{Debate sobre la gobernanza económica europea: la ambiciosa propuesta española}

Los líderes europeos decidieron, en el Consejo Europeo de Octubre de 2014, reflexionar sobre la gobernanza del euro y dirigieron un mandato al presidente de la Comisión Europea para trabajar en la "preparación de nuevos pasos hacia una mejor gobernanza económica en la Eurozona". Esta tarea debía ser realizada en estrecha colaboración con el presidente de las cumbres del Euro, el presidente del Eurogrupo y el presidente del Banco Central Europeo.

Los cuatro presidentes presentaron el 12 de Febrero una "nota analítica" en la que valoraban el estado de la Unión Económica y Monetaria (UEM), identificaban sus principales fallos que han salido a la luz con la crisis y describían las medidas adoptadas hasta entonces para hacerles frente. Con este análisis, la nota preparaba el terreno para el posterior debate sobre los futuros pasos a dar en la mejora de la Unión Económica.

Siguiendo este planteamiento, los diferentes países de la Eurozona han ido enviando sus propuestas; Francia y Alemania remitieron a Bruselas un documento conjunto, e Italia hizo lo mismo a mediados de Mayo. En ambos casos la ambición por introducir grandes cambios parece haberse relajado, quizás por la llegada de la recuperación económica y los documentos planteaban propuestas de menor alcance y a muy largo plazo.

Sin embargo, la aportación de España apunta hacia cambios de calado ante la constatación de que Europa sigue siendo "vulnerable a choques asimétricos", tal como refleja el documento enviado a la Comisión el 27 de Mayo.

El gobierno de Mariano Rajoy se muestra especialmente crítico con el papel del BCE al señalar en el documento que "la orientación de la política monetaria única ha demostrado ser inadecuada para determinados Estados miembros en los últimos años y ha generado choques asimétricos". "En algunos países, la política monetaria fue excesivamente expansiva, y creó condiciones financieras que promovieron el excesivo endeudamiento y la acumulación de desequilibrios", apunta también el documento en clara referencia a la burbuja inmobiliaria española.

El documento también señala que en la Eurozona no existe suficiente movilidad laboral, circunstancia que amplificó los problemas puesto que "los desequilibrios no pudieron ser absorbidos con un trasvase de trabajadores entre países, sino por ajustes en el número de empleados y desempleados en cada país".

Y destaca también que la fragmentación del Mercado Interior ha dificultado el éxito de la Unión Monetaria, siendo especialmente destacable la fragmentación del sector bancario minorista que, al igual que las carencias en la movilidad laboral, agravó la acumulación de los desequilibrios. 
Según el gobierno español, el rediseño de la política económica común exigiría:

- alcanzar niveles suficientes de movilidad laboral,

- alcanzar una Unión Fiscal sólida que incluya tres elementos: la transferencia de soberanía a la Unión en políticas de ingresos y gastos nacionales, un presupuesto común en la Eurozona e instrumentos de deuda comunes,

- y completar el mercado interior y, en particular, solventar la fragmentación del mercado financiero asegurando una integración adecuada del sector bancario minorista.

Madrid propone un enfoque gradual, inspirado en el proceso de convergencia de Maastricht que culminó con la adopción de la moneda única.

La participación de cada Estado en las diferentes fases estaría condicionada al cumplimiento de los nuevos criterios de convergencia definidos.

En una primera fase, en el horizonte de 2017, el gobierno español plantea mejorar y reforzar los procesos de coordinación de políticas económicas, aumentar la movilidad laboral entre países y completar la Unión Bancaria.

En una segunda fase, prevista para 2019, el gobierno plantea un cambio en el mandato del Banco Central Europeo. Aunque el primer objetivo de Fráncfort debe seguir siendo la inflación, España propone hacer explícita una segunda meta relacionada con su contribución a la prevención de divergencias macroeconómicas y desequilibrios entre países.

También propone la creación de una capacidad fiscal común de naturaleza cíclica y vinculada a la inversión pública con una capacidad de endeudamiento limitada. La emisión de deuda estaría sujeta a condiciones estrictas y dependería de las necesidades cíclicas, de tal forma que la deuda emitida en los "malos tiempos" debería ser reabsorbida en los "buenos tiempos".

Los progresos en la integración económica deberían acompañarse con una integración política más profunda. En esta fase, sería necesaria una autoridad responsable de la política económica de la zona euro, algo así como un Ministro de Finanzas de la eurozona. Dicha autoridad sería responsable de la capacidad fiscal limitada, estaría al cargo de la coordinación y supervisión del proceso de convergencia y promovería el análisis de la gestión de la deuda pública.

En una tercera fase, más allá de 2020, Madrid propone que la capacidad fiscal limitada de paso a una verdadera Unión Fiscal que integre los tres elementos centrales: la transferencia de soberanía en cuanto a las políticas fiscales de ingresos y gastos al nivel europeo de decisión, un presupuesto común de la zona euro y la creación de instrumentos comunes de deuda. 


\section{Acuerdo político sobre el Plan Juncker}

Las instituciones europeas lograron a finales de Mayo desbloquear el llamado plan Juncker que permitirá movilizar, previsiblemente, $315.000 \mathrm{mi}-$ llones de euros de inversión pública y privada entre 2015 y 2017.

El llamado Fondo Europeo de Inversiones Estratégicas (FEIE), que eventualmente podría estar operativo a finales del verano de 2015, funcionará con una dotación de 16.000 millones de euros procedentes del presupuesto comunitario y con 5.000 millones de euros del Banco Europeo de Inversiones (BEI).

Los 16.000 millones estarán provisionados al 50\%, es decir, con 8.000 millones de euros. Inicialmente, la garantía del Fondo debía constituirse con 2.000 millones del margen de los presupuestos anuales de la UE, con 3.300 millones del programa "Conectar Europa" de infraestructuras y con otros 2.700 millones de Horizonte 2020 de investigación e innovación.

Sin embargo, el Parlamento Europeo defendía reducir el impacto sobre estos dos programas comunitarios incluidos en el presupuesto de la UE, y finalmente logró reducir dicho impacto en 1.000 millones de euros, siendo sustituidos por 543 millones del margen no utilizado del presupuesto de 2014 y 457 millones del de 2015.

De esta forma, y según el acuerdo político alcanzado, el fondo de garantía del FEIE se nutrirá de 3.000 millones de euros del remanente de los presupuestos anuales, de 2.800 millones de "Conectar Europa" y de 2.200 millones de Horizonte 2020.

Los representantes del Parlamento Europeo y del Consejo consiguieron, por fin, poner fin a varios meses de conflicto sobre el modelo de financiación planteado por la Comisión Europea para su plan de inversiones.

\section{La Comisión propone una multa a España por el falseamiento del déficit público}

La Comisión Europea aprobó formalmente el 7 de Mayo una propuesta de imponer a España una multa de 18,93 millones de euros por la manipulación y "negligencia grave" respecto a las estadísticas del déficit y la deuda en la Comunidad Valenciana, falseamiento que se prolongó durante más de 20 años, entre 1988 y 2011 y que sólo se corrigió en 2012.

Se trata de la primera vez que el ejecutivo comunitario tomaba la decisión de sancionar a un Estado miembro por falsear sus estadísticas basándose en las nuevas normas de la UE que se aprobaron en 2011 a raíz del caso de Grecia. Por ello, y por el carácter no retroactivo de la legislación, la multa se refiere sólo al periodo 2011-2012. 
El caso se originó en Mayo de 2012, cuando las autoridades españolas informaron a Eurostat, la agencia estadística de la Unión, de que el déficit de 2011 tenía que revisarse al alza cuatro décimas de PIB (unos 4.000 millones) por la detección de gastos no registrados en Valencia y Madrid.

Eurostat investigó y descartó problemas en el caso de Madrid. No ocurrió lo mismo con la Comunidad Valenciana, donde se detectó una partida de gasto sanitario oculto. Comprobó que la intervención general de esa administración "había enviado sistemáticamente información incorrecta a lo largo de muchos años".

En su decisión de multar a España, Bruselas tuvo en cuenta una serie de "factores atenuantes" que le llevaron a reducir el importe de la multa, cuyo valor de referencia inicial era de 94,65 millones de euros. En particular, concluía que la tergiversación de las cifras "no fue intencionada sino que se debió a una negligencia grave de una entidad que actuó por su cuenta".

En concreto, el informe de la Comisión apuntaba como único responsable a la Intervención General de la Comunidad Valenciana, que había ignorado los informes del Tribunal de Cuentas valenciano y los avisos de la Consejería de Sanidad. Además, valoraba positivamente que las autoridades españolas hubieran cooperado plenamente en la investigación y que hubiera puesto fin a las irregularidades. La multa tiene así un carácter meramente simbólico y queda muy lejos del máximo previsto en la legislación de la UE, que en el caso de España sería 2.000 millones de euros (el 0,2\% del PIB).

"Nuestra investigación ha concluido que la comunidad autónoma de Valencia cometió una negligencia grave al no registrar gastos sanitarios", señaló la comisaria responsable de Eurostat, Marianne Thyssen. "Valencia ha informado incorrectamente sobre el gasto sanitario y ha enviado datos incorrectos sobre el gasto público a las autoridades estadísticas españolas. Como resultado de esto, durante mucho tiempo, los datos enviados por España a Eurostat en el contexto del procedimiento por déficit excesivo no eran plenamente correctos", agregó.

La multa todavía tiene que ser aprobada por los ministros de Economía de la UE por mayoría cualificada, en una votación en la que no podrá participar el titular español, Luis de Guindos.

\section{Cuestiones generales de la actualidad económica}

\section{BCE: Compra masiva de Deuda pública}

El BCE puso en marcha en Marzo un programa de compras de deuda pública y privada a gran escala, conocido como "Flexibilización Cuantita- 
tiva" (QE, "Quantitative Easing” en inglés) que ya había sido anunciado en Enero por el presidente de la institución, Mario Draghi.

Esta "medida no convencional" de política monetaria prevé que el Banco realice estas compras a un ritmo de 60.000 millones de euros al mes hasta finales de septiembre de 2016. El presidente del BCE señalaba que este programa contribuiría a conseguir un "rebote de la inflación" y a reducir las primas de riesgo (los tipos de interés que pagan los países por su deuda en términos de diferencial respecto los intereses de los bonos alemanes) hasta llegar incluso a tipos de interés negativos. En Marzo Alemania ya cobraba intereses a quienes invertían en su deuda a plazos de hasta cinco años e incluso la deuda española entraba en territorio negativo para los plazos más cortos.

Además, el Banco confiaba en que esta medida mejore las condiciones de financiación de empresas y particulares.

La intervención del BCE debía realizarse a través de los Bancos Centrales de los países de la Eurozona, quienes, desde Marzo de 2015, están comprando bonos con una calificación mínima BBB en los mercados secundarios, aunque con la condición, impuesta por Alemania, de que únicamente el 20\% del riesgo de las compras se mutualiza. De esta forma, la mayor parte de las posibles pérdidas o ganancias que se produzcan se integrarán directamente en los balances de cada uno de los Bancos Centrales nacionales.

Las compras en los 19 meses de duración del programa sumarán 1,14 billones de euros, y en torno a 100.000 millones serán compras de bonos españoles, lo que significa alrededor del 10\% de la deuda pública.

La decisión del BCE, que se produjo cinco años después de que comenzara la crisis de deuda en la Eurozona, fue calificada de "decisión histórica", puesto que suponía el esperado cambio de rumbo de Frankfurt. El estímulo, superior al billón de euros, deberá permitir que el dinero deje de fluir hacia la deuda pública y se canalice hacia otras actividades, lo que facilitará la recuperación y el paulatino regreso a mayores niveles de inflación.

\section{Mecanismo Europeo de Estabilidad: primera emisión de deuda con intereses negativos}

En Marzo, el Mecanismo Europeo de Estabilidad, MEDE, colocó 3.000 millones de euros en deuda a dos años y medio con un tipo de interés del $-0,07 \%$, lo que significó la primera emisión con tipos negativos del fondo de rescate permanente de la Eurozona.

La operación había registrado una gran demanda y las órdenes de inversores de todo el mundo superaron los 9.000 millones de euros, lo que se tra- 
dujo en unas declaraciones de satisfacción por parte del director financiero del Fondo, Christophe Frankel, quien señaló que "la fortaleza y la alta calidad de las solicitudes muestran que, de nuevo, hemos cumplido las demandas de los inversores".

\section{Acuerdo Trasatlántico UE-EEUU: negociaciones pospuestas}

El Pleno del Parlamento Europeo decidió el 10 de junio posponer su autorización a la Comisión Europea para avanzar en las negociaciones con Estados Unidos encaminadas a concluir el acuerdo de libre comercio (TTIP por sus siglas en inglés, Transatlantic Trade and Investment Partnership) entre los dos principales bloques comerciales del mundo.

"En vista de que se han recibido más de 200 enmiendas a las recomendaciones sobre el TTIP se ha decidido que la votación que se iba a celebrar hoy ya no se va a realizar", explicó el Parlamento mediante un comunicado. La división de los eurodiputados la personifican, por un lado, los populares, liberales y reformistas que apoyan sin fisuras el acuerdo y, por otro, los grupos más a la izquierda como los verdes o la izquierda europea que rechazan el tratado. De esta forma, la llave para continuar la negociación está en manos de los socialdemócratas que se muestran divididos al respecto, lo que ha llevado al Parlamento Europeo a posponer la votación.

A finales de Mayo la comisión de Comercio Internacional de la Eurocámara sí había aprobado esta autorización, aunque la comisaria de Comercio, Cecilia Malmström se mostró pesimista sobre la posibilidad de cerrar el acuerdo antes de finalizar 2015.

Los eurodiputados habían establecido algunas "líneas rojas" como la protección de los servicios públicos europeos, el respeto a los estándares medioambientales, la transparencia en las negociaciones, una mayor participación de la sociedad civil en el proceso y el rechazo al Tribunal de arbitraje en los términos en que lo planteaba Washington.

Fuentes del Parlamento ya destacaron entonces el "esfuerzo" de la comisaria Malmström por hacer más transparentes las negociaciones y, también, la "positiva" modificación del Tribunal que la política sueca ha planteado.

La principal polémica que, en efecto, ha generado el Tratado de Libre Comercio es la creación de dicho Tribunal de arbitraje, ante la posibilidad de que las multinacionales pudieran recurrir y revocar leyes estatales justificándose en la protección de sus inversiones, circunstancia que ha sido interpretada como una pérdida de soberanía de los Estados a favor de las grandes corporaciones americanas.

Ante dicha polémica, la propuesta de la Comisión en relación a esta corte ha experimentado dos modificaciones importantes. Por una parte, se 
plantea que los miembros del Tribunal deberán ser personas libres de conflictos de interés y con cualificación jurídica en sus países. Se trataría de evitar que las mismas personas actúen como jueces en un arbitraje y como abogados en otros, o que, tras mediar en un conflicto acaben posteriormente en el consejo de administración o a sueldo de la empresa sobre la que tomaron una decisión. Y la segunda novedad es la posibilidad de establecer un tribunal de apelación permanente con capacidad de confirmar o revocar el resultado del arbitraje.

Otro punto que ha desatado las críticas al Tratado es la eventual importación de de carne hormonada o de transgénicos de EE UU en países europeos donde no están autorizados. En este tema, la Comisión Europea ya ha anunciado su intención de aprobar en un futuro próximo un proyecto legislativo sobre comercialización de productos transgénicos que permitirá a cualquier socio europeo vetar su entrada aunque estén autorizados en el resto del continente. Y aunque el objetivo inicial de las conversaciones era la supresión de todos los aranceles aduaneros, las dos partes ya tienen encima de la mesa una extensa lista de "productos agrícolas e industriales calificados como sensibles", que quedarían o bien excluidos de la liberalización o sujetos a periodos transitorios más largos.

Por otra parte, desde muchos colectivos sociales se ha insistido en la idea de la fuerte desregulación del mercado laboral estadounidense (sin salario mínimo ni derecho a la huelga) y su posible traslación al mercado europeo. Recalcan estas fuentes que Estados Unidos solo han refrendado dos de los ocho convenios de la Organización Internacional del Trabajo (los contrarios a la esclavitud o al trabajo esclavo). No lo ha hecho todavía en lo referente a la negociación colectiva ni al derecho de organización y asociación.

Para el ejecutivo español este acuerdo de libre comercio con la primera economía mundial tiene "carácter estratégico", teniendo en cuenta que Estados Unidos es el sexto cliente mundial de las exportaciones españolas y es también el primer socio comercial de España fuera de la UE, con un flujo total de intercambios de bienes y servicios de 20.913 millones de euros en el último ejercicio.

Por lo que respecta a las inversiones, España se ha convertido en el noveno país con mayor volumen de inversión en Estados Unidos, en donde ya están presentes más de 700 compañías españolas que dan empleo a 70.000 personas. Por su parte, este país es el segundo inversor extranjero en nuestro país, con un stock acumulado cercano a los 40.000 millones de euros y en 2014 ocupó el primer lugar en inversiones productivas con 3.516 millones de euros, lo que supuso el 19,9 por ciento de la inversión bruta total.

Los informes de la Administración comercial española destacan como sectores económicos potencialmente más beneficiados por el TTIP al automóvil, la aeronáutica, la energía y la agroalimentación. 


\section{Competencia-ayudas públicas: investigación sobre las ayudas a las compañías eléctricas de once países y al sector bancario de cuatro países}

La Comisión Europea anunció a finales de Abril su intención de investigar las ayudas públicas concedidas a las compañías eléctricas en España y en otros 10 países, para garantizar que no se haya favorecido a determinados productores energéticos ni se hayan establecido barreras que obstaculicen el flujo entre Estados europeos.

Estas ayudas están dirigidas a apoyar las inversiones de las eléctricas destinadas a cubrir los potenciales déficits energéticos futuros y a garantizar, por tanto, la disponibilidad constante de producción eléctrica y evitar apagones. El objetivo es que el suministro satisfaga siempre la demanda y que la UE pueda tener un mercado "interconectado, integrado y seguro".

Sin embargo, Bruselas pretende averiguar si estos llamados "mecanismos de capacidad", introducidos por gran parte de los gobiernos europeos para apoyar la inversión en las centrales eléctricas no distorsionan la competencia o rompen el mercado único europeo al levantar barreras a competidores externos.

Además de España, el resto de países investigados son Francia, Alemania, Italia, Polonia, Bélgica, Croacia, Dinamarca, Irlanda, Portugal y Suecia. En todos estos países existen mecanismos de capacidad o planes para ponerlos en marcha.

Y aunque la Comisión reconoce que tales medidas pueden estar justificadas, sus Directrices de 2014 también incluían criterios para evaluar si los mecanismos de capacidad se ajustan a las normas sobre ayudas estatales. Los Estados miembros han de poder demostrar que las medidas son necesarias y deben cerciorarse de que los mecanismos de capacidad no distorsionan la competencia en el mercado único de la UE, no favoreciendo, por ejemplo, a determinados productores o tipos de tecnología ni poniendo obstáculos que impidan el flujo de electricidad entre países de la UE.

"Los gobiernos tienen un interés legítimo de garantizar que haya un suministro suficiente de electricidad y que los hogares y la industria no sufran apagones", señaló la comisaria de Competencia, Margrethe Vestager, pero también dejó claro que su papel es garantizar que "las medidas públicas para impulsar las inversiones en el suministro de electricidad no favorezcan indebidamente a determinados productores o tecnologías, o creen trabas al comercio a través de las fronteras nacionales".

Se trata de la primera investigación sectorial que el ejecutivo comunitario lanza en materia de ayudas públicas y aunque inicialmente se centrará en 11 Estados miembros, fuentes de la institución señalaron que se reserva el derecho de ampliarla a otros países. 
Otro sector investigado por las ayudas públicas recibidas es el bancario. A comienzos de Abril, la Comisión Europea decidía iniciar una investigación preliminar para determinar si las garantías que ha concedido España a los activos fiscales diferidos de la banca con el fin de que computen como capital de máxima calidad constituyen ayudas públicas ilegales. La petición de información de Bruselas, que inicialmente no es una investigación formal, afecta además a Grecia, Italia y Portugal, que también utilizan este tipo de incentivos fiscales.

Los activos fiscales diferidos (DTA, por sus siglas en inglés) consisten en apuntar como un activo en el balance del banco los futuros ahorros en impuestos por tener pérdidas, aunque este ahorro sólo puede materializarse cuando la entidad vuelva a obtener beneficios.

Las normativas europea e internacional establecen que estos activos deben deducirse del capital de máxima calidad de los bancos, de manera que para evitar esta deducción los DTA deberían estar garantizados. Y fueron estas garantías las que, en efecto, aprobó el gobierno de Rajoy a través de un decreto. Aunque el ejecutivo cifró estas garantías en 30.000 millones, la cifra real superó los 40.000 millones, según los datos publicados por los propios bancos.

"Necesitamos estudiar cómo funcionan estas medidas fiscales en cada Estado y decidir si se consideran ayudas públicas o no", explicaba un portavoz del ejecutivo comunitario.

Aunque otros países como Alemania o Francia han utilizado los DTA en el pasado, la Comisión resaltaba en Abril que son los cuatro países del sur de la UE "los únicos" que los siguen utilizando como beneficio fiscal.

La supresión del aval público obligaría a los bancos a sustituir, en el cómputo del capital de máxima calidad, los avales públicos por otros recursos, es decir, les obligaría a cumplir los ratios de solvencia con capital procedente del mercado.

La banca española, por su parte, manifestó que ese cambio debía supeditarse a la supresión de otras excepciones similares de las que se beneficia el resto del sector europeo. El Banco Central Europeo estima que, de hecho, gracias a esas excepciones, la banca europea (incluida la española), sumó 126.200 millones de euros en capital de máxima calidad, mejorando su ratio de solvencia en más de un punto.

\section{Competencia-abuso de posición de dominio: acusaciones a Google y Gazprom}

En Abril, la Comisión Europea hizo pública su acusación a Google de abuso de posición dominante por favorecer sus productos en las búsquedas 
en internet; y anunciaba también el inicio oficial de otra investigación antimonopolio contra su sistema operativo para móviles, Android.

La comisaria de competencia, Margrethe Vestager, señalaba durante la presentación de los cargos contra el gigante norteamericano que, tras cinco años de investigación preliminar, la acusación se había centrado en un aspecto muy concreto como es la discriminación que Google realiza en las búsquedas de su servicio de comparación de precios. El buscador, señalaba la comisaria, coloca sistemáticamente en los primeros puestos sus propios servicios especializados de comparaciones de precios independientemente del tipo de búsqueda, "algo que no parece reflejar sus méritos", alegaba Vestager.

En esta primera etapa del procedimiento, la firma tecnológica tendrá derecho a defenderse y la Comisión podrá reconsiderar su postura, pero en el caso de que Bruselas confirme su acusación, podría imponer una sanción equivalente al 10\% de su facturación anual, es decir, unos 6.200 millones de euros, y la obligación de que Google realice cambios estructurales en su buscador para poner fin al abuso de su dominio.

Se trata, en efecto, de una pieza separada puesto que Bruselas también anunciaba la apertura de una investigación para determinar si Google vulnera la competencia en el mercado comunitario al llegar a acuerdos con los fabricantes de móviles para que utilicen su sistema operativo Android que incluye un buen número de aplicaciones y servicios de Google. Y también analizará si la compañía americana ha impedido que estos fabricantes de móviles inteligentes y tabletas desarrollen y comercialicen versiones modificadas y potencialmente rivales de Android.

Independientemente de estos dos casos, la Comisión señaló que "sigue investigando activamente" otras tres objeciones que plantea a Google, como son la copia de contenidos de webs rivales, la exigencia de exclusividad con los editores al obligarles a mostrar los anuncios de Google en las búsquedas y las restricciones que la compañía impone para que los anunciantes puedan trasladar sus campañas a otras plataformas.

También en Abril la Comisión Europea anunciaba que había notificado al gigante ruso del gas Gazprom sus acusaciones por presunto abuso de posición dominante en el mercado del suministro y la distribución de gas en Europa central y oriental.

Según el ejecutivo comunitario, Gazprom habría compartimentado el mercado del gas en esa región "reduciendo la capacidad de reventa transfronteriza de sus clientes", lo que le permitiría "facturar precios no equitativos en algunos Estados miembros de la UE". La Comisión también sospecha que la posición dominante de Gazprom le habría permitido "subordinar el suministro de gas a la obtención de compromisos distintos de parte de los mayoristas" en las infraestructuras que transportan el gas. 
"El gas es un bien esencial para nuestra vida cotidiana", declaraba la comisaria de Competencia, Margrethe Vestage. “

La Comisión había iniciado una investigación preliminar contra Gazprom en agosto de 2012 y retuvo estos cargos sobre las presuntas prácticas anticompetitivas de la empresa en los mercados de Bulgaria, República Checa, Estonia, Hungría, Letonia, Lituania, Polonia y Eslovaquia.

\section{Bruselas recurre la decisión del Tribunal sobre las deducciones fiscales aplicadas por empresas españolas por la adquisición de empresas extranjeras}

Un nuevo capítulo en la batalla judicial sobre las ayudas millonarias concedidas por el gobierno español a grandes multinacionales se inició en Enero cuando la Comisión Europea decidió recurrir la sentencia del Tribunal General de la UE que avaló la norma que permitía a empresas de la talla de Telefónica, Banco Santander, Iberdrola o Abertis aplicar importantes deducciones fiscales por la adquisición de otras compañías en el exterior.

La posición del ejecutivo comunitario contra estas ayudas no es nueva puesto que ya había declarado ilegal esta práctica, y en Octubre de 2014 obligó al gobierno español a recuperar las ayudas a estas grandes corporaciones, aunque un mes después, el Tribunal de Luxemburgo hizo público un fallo contrario a las tesis de Bruselas.

La Comisión consideraba que el régimen fiscal español sobre la adquisición de participaciones en empresas extranjeras, basado en una interpretación administrativa de la norma del Impuesto de Sociedades, no se ajustaba a las normas sobre ayudas estatales de la UE al otorgar unos beneficiarios fiscales de manera selectiva respecto a las empresas que realizan adquisiciones nacionales.

Tras el dictamen de la Comisión, las empresas que se habían beneficiado de la interpretación administrativa se veían obligadas a reembolsar los beneficios fiscales y, aunque ni el gobierno español ni Bruselas habían desvelado el nombre de las compañías afectadas, sí trascendió que, entre ellas, se encontraban Telefónica, Banco Santander e Iberdrola.

Sin embargo, apenas un mes después, el 7 de Noviembre, el Tribunal comunitario emitía dos resoluciones a los recursos presentados por el Banco Santander y por Autogrill España. Los jueces señalaban en su sentencia que la Comisión no había logrado demostrar que el régimen fuera selectivo y que estaba diseñado para conceder ventajas fiscales exclusivamente a grandes empresas. El Tribunal contradecía, así, el dictamen de la Comisión, una decisión especialmente insólita puesto que muy rara vez sucede que la 
Corte comunitaria anula las decisiones del ejecutivo comunitario en el ámbito de las ayudas de Estado.

\section{Tribunal de Justicia: nuevo dictamen en contra de la Ley Hipotecaria española}

Uno de los Abogados generales del Tribunal de Justicia de la UE, Maciej Spuznar, emitió un dictamen el 13 de Mayo en el que señalaba que el plazo de un mes para recurrir los desahucios en España, tal como establece la ley hipotecaria de 2013, "no es razonable". "El plazo de un mes no es adecuado para preparar e interponer un recurso eficaz", afirmaba el letrado.

Y aunque la opinión del abogado de la corte no es vinculante, sí se considera especialmente significativa de cara a la deliberación que los magistrados europeos debían comenzar a continuación para hacer pública la sentencia definitiva en los meses siguientes.

El principal problema, sin embargo, no parece residir en el plazo de un mes, que en cualquier caso se considera insuficiente, sino en el hecho de que la legislación española equipara la publicación de la ley en el BOE a una notificación de carácter procesal.

La directiva de la UE sobre cláusulas abusivas "se opone a una disposición nacional como la española" porque, según Spuznar "lo que plantea problemas es precisamente el hecho de que el plazo comience a correr a partir del día siguiente al de la publicación del texto legal en el BOE, sin haber sido notificado a las partes demandadas en los procedimientos de ejecución". En este plazo sin que exista notificación, las familias desahuciadas ven dificultado "en exceso" el ejercicio de sus derechos como consumidores.

La decisión de Mayo se suma a la media decena de sentencias negativas que el Tribunal de Justicia acumula ya contra la legislación hipotecaria española. La Comisión Europea está negociando con las autoridades españolas la introducción de nuevos cambios en la norma y no descarta interponer un procedimiento de infracción.

\section{Competencia: autorización de compra de Jazztel por parte de Orange}

La Comisión Europea autorizó en Mayo la compra de la operadora española de telecomunicaciones Jazztel por parte de la francesa Orange, aunque con condiciones para "garantizar una competencia efectiva" en el mercado español de acceso fijo a internet. La operación, valorada en 3.400 millones de euros, fusionará al tercer y cuarto proveedor de servicios de telecomunicaciones fijas en España. 
“Algo muy importante antes de aprobar la absorción de Jazztel por parte de Orange era asegurarse de que los consumidores españoles no tendrían que soportar precios más elevados por el acceso fijo a internet", señaló la comisaria europea a cargo de políticas de competencia, Margrethe Vestager.

Tras un análisis previo de la operación, la Comisión concluía que la reducción de cuatro a tres operadores en el mercado español (la nueva surgida de la absorción, Movistar y Vodafone) hubiese desalentado la aparición de nuevos proveedores de servicios por "las elevadas inversiones necesarias para introducirse en el mercado minorista" de servicios de acceso a internet fijo; fue por ello que Orange hizo una serie de propuestas que fueron aceptadas por Bruselas para autorizar la operación.

En primer lugar, se comprometió a vender una red de fibra óptica que alcanza de 700.000 a 800.000 unidades "Esta red de alta velocidad abarca trece municipios urbanos situados en cinco de las mayores ciudades españolas: Madrid, Barcelona, Valencia, Sevilla y Málaga”, indicaba la Comisión.

Orange propuso asimismo que el comprador de la red de fibra óptica tenga acceso mayorista a la red de ADSL de Jazztel durante un periodo de hasta ocho años para un número ilimitado de abonados y planteó su compromiso de permitir al comprador competir inmediatamente en el $78 \%$ del territorio español.

El tercer compromiso planteado por la empresa francesa es que si el comprador no dispone de acceso a una red de telecomunicaciones móviles, incluidos los servicios de 4G, Orange deberá facilitar al comprador acceso mayorista a tales servicios móviles en condiciones competitivas y, en cualquier caso, en condiciones tan favorables como las que Orange ya otorga a Jazztel.

"Las medidas correctivas tomadas en su conjunto garantizan que un cuarto proveedor de ámbito nacional pueda introducirse en el mercado español y competir eficazmente", concluía la Comisión en su comunicado.

\section{Inmigración: plan de acogida a solicitantes de asilo}

La Comisión Europea anunció el pasado 27 de Mayo un plan para acoger en los países miembros a 40.000 solicitantes de asilo sirios y eritreos llegados a Grecia e Italia en los últimos meses.

A España le correspondería acoger a 4.288 personas en dos años, es decir, el 10,72\%, mientras que Reino Unido, Irlanda y Dinamarca quedarían exentos de ningún compromiso por las disposiciones específicas que, en esta materia, prevén los Tratados comunitarios. 
Aunque el ejecutivo comunitario prefiere no hablar de "cuotas", el reparto propuesto ha desatado una encendida polémica entre los Estados, en particular por la oposición de países como Francia, España, Polonia, las repúblicas bálticas y Hungría, que discrepan de los criterios seguidos para calcular la recepción de asilados en los Estados europeos (un 40\% dependiendo del PIB, un $40 \%$ del número de habitantes, un 10\% del desempleo y un $10 \%$ de los esfuerzos anteriores en la acogida de inmigrantes).

Madrid ya ha reiterado su desacuerdo con el este sistema de reparto puesto que considera que la tasa de paro tendría que tener un peso mayor, y por tanto España debería acoger un número menor de demandantes de asilo.

La decisión final, que en todo caso deberá ser adoptada por los Estados miembros mediante el sistema de mayoría cualificada, se articulará por el llamado "mecanismo de emergencia" que prevé el Tratado de funcionamiento de la UE en su artículo 78.3 sobre situaciones en las que "uno o varios Estados miembros se enfrentan a una situación de emergencia caracterizada por la afluencia repentina de nacionales de terceros países".

Junto con este Plan, Bruselas también planteaba que los Veintiocho acepten voluntariamente a otras 20.000 personas en situación de emergencia en todo el mundo (y en especial África y Oriente Medio) que demandan asilo en Europa. En este caso, a España le correspondería la acogida de 1.549 personas. 